\title{
The Assessment of the Relationship Between ABO Blood Groups and Covid-19 Infection
}

\author{
Sude Hatun AKTIMUR ${ }^{1}$, Ahmet SEN ${ }^{2}$, Bahadir YAZICIOGLU ${ }^{3}$, \\ Ahmet Kursad GUNES ${ }^{4}$, Serhat GENC 5 \\ ${ }^{1}$ Samsun Training and Research Hsopital, Department of Heamatology, Samsun \\ ${ }^{2}$ University of Health Sciences, Faculty of Medicine, Department of Anesthesiology and Reanimation, Samsun \\ ${ }^{3}$ Samsun Training and Research Hsopital, Department of Family Medicine, Samsun \\ ${ }^{4}$ Ankara City Hospital, Department of Internal Medicine and Heamatology, Ankara \\ ${ }^{5}$ Uskudar University Faculty of Medicine, Department of Health Management, Istanbul, TURKEY
}

\begin{abstract}
The new coronavirus disease-2019 (COVID-19) is rapidly spreading around the world and has been declared an outbreak by WHO. However, the effect of blood groups on COVID-19 infection and the severity of the disease is unclear. The aim of this study is to determine the relationship between ABO blood group and susceptibility to COVID-19 infection and whether the blood group will be a biomarker for COVID-19 infection. Patients diagnosed with SARS-CoV-2 between March and May 2020 were included in this study. In order to compare the blood groups of the patients with the healthy group, patients who had previously performed ABO blood group analysis in the blood bank between February and May 2020 were included as the control group. Demographic data, clinical data, underlying comorbidities, laboratory findings and clinical results (hospitalization, need for intensive care, mortality) were obtained from the electronic medical records. A total of 179 patients with confirmed COVID-19 and 5200 healthy control patients were included in the study. Patients with COVID-19 showed a distribution of $62.01 \%$ in group A,9.50\% in group B, 8.94\% in group $A B$ and $19.55 \%$ in group $O$. In group A, length of stay in Intensive Care Unit was longer (10.42 \pm 11.61 days; $p=0.013)$. Compared to the blood groups of the healthy control group, COVID-19 patients had higher A blood group than the healthy group (62\& vs.46.6\%; $p<0.001)$ and lesser of the O blood group (19.6\% vs. 34.7\%; p< 0.001).Blood group A can be used as a predictive biomarker for COVID-19 disease.In addition, we concluded that the group A had a higher risk for COVID-19 disease and severity.
\end{abstract}

Keywords: COVID-19, SARS-CoV-2, ABO blood groups, Antibody, Mortality

\section{INTRODUCTION}

On December 31, 2019, severe acute respiratory syndrome caused by coronavirus 2 (SARS-CoV-2) appeared in Wuhan, China's Hubei province. ${ }^{1}$ In February, the World Health Organization (WHO) named the disease caused by SARS-CoV-2 as Coronavirus Disease 2019 (COVID-19). On March 11, the COVID-19 outbreak was announced as a pandemic. $^{2}$ The spread in the United States and Europe is growing steadily, around 6 million people worldwide are infected and COVID-19 deaths have more than $300.000 .^{3}$
The use of biomarkers to predict susceptibility to SARS-CoV-2 is not well defined. To date, few studies have reported that $\mathrm{ABO}$ blood groups are associated with susceptibility to SARS-CoV-2., ${ }^{45}$ Recent studies show that age, male sex, and the presence of some chronic diseases (e.g., cardiovascular disease, hypertension, diabetes, chronic obstructive pulmonary disease) pose a risk for SARS-Cov-2 infection and disease severity. ${ }^{6}$

Red blood cells have a range of polysaccharides and proteins on their surface, which are known as blood group antigens. ${ }^{7}$ 
Landsteiner's ABO blood groups are carbohydrate epitopes on the surface of human cells. Various studies have been conducted to find the relationship of blood groups with infectious and non-infectious diseases. ${ }^{8}{ }^{89}$ Viral infection sensitivity has been previously shown to be associated with the $\mathrm{ABO}$ blood group. ${ }^{10,11}$ Moreover, there is a relationship between blood group and SARS coronavirus infection. ${ }^{12}$

There are a limited number of studies evaluating the susceptibility to COVID-19 disease with ABO blood groups. ${ }^{5,13}$ The aim of this study is to determine the relationship between $\mathrm{ABO}$ blood group and susceptibility to COVID-19 infection and whether the blood group will be a biomarker for COVID-19 infection.

\section{PATIENTS and METHODS}

Patients diagnosed with SARS-CoV-2 between March and May 2020 were included in this study. The study was accepted by the Local Ethics Committee with GOKA / 2020/8/14. Written consent was obtained from all participants. The study was designed in accordance with the Helsinki Declaration.

The diagnosis of COVID-19 was confirmed by the real-time polymerase chain reaction (RT-PCR) test of SARS-CoV-2 on nasal and pharyngeal swab samples from patients. Demographic data, clinical data,
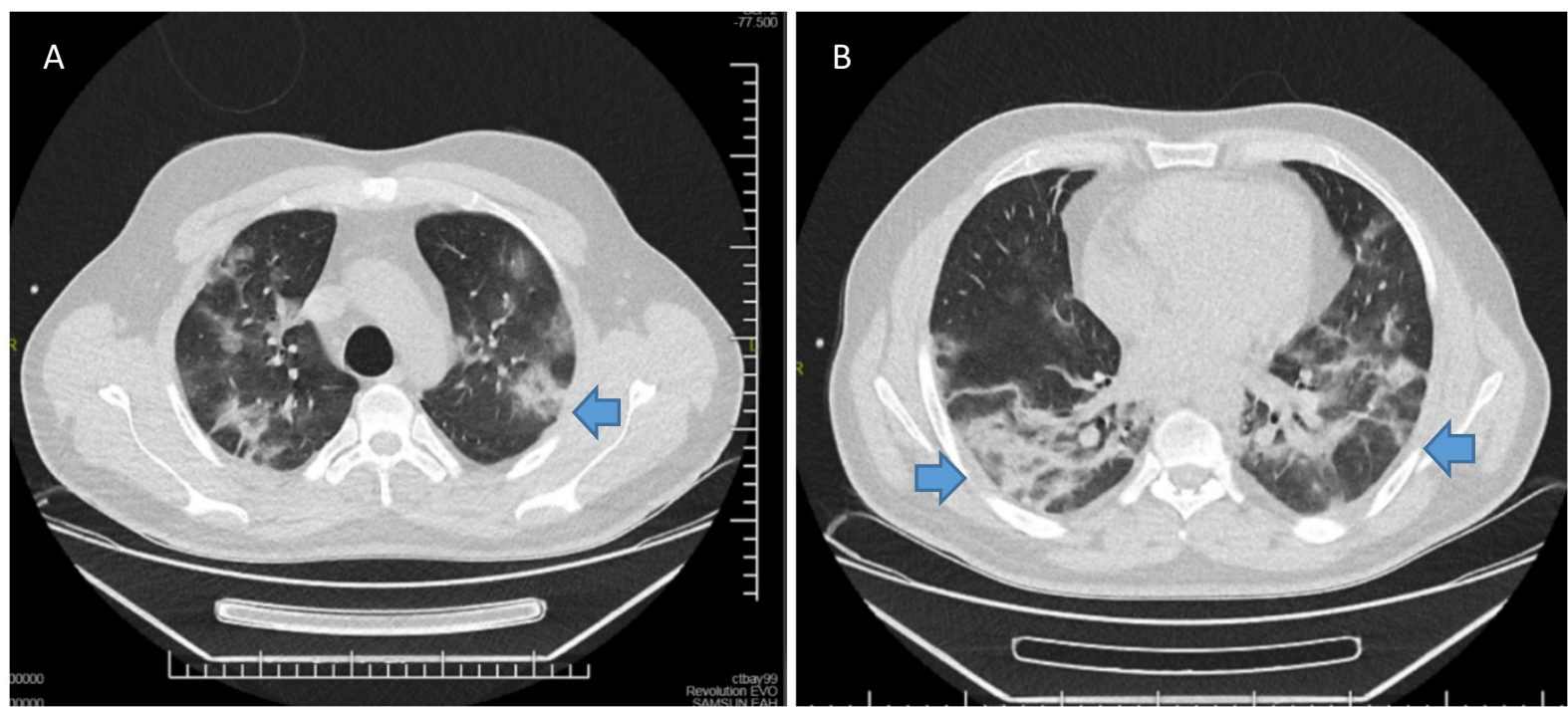

Figure 1A-B. Radiological findings of COVID-19 patient. Posterior and peripherally located, ground glass lesions (Arrow).

underlying comorbidities, laboratory findings and clinical results (hospitalization, need for intensive care, mortality) were obtained from the electronic medical records (Figure 1).

In order to compare the blood groups of the patients with the healthy group, patients who had previously performed $\mathrm{ABO}$ blood group analysis in the blood bank between February and May 2020 were included as the control group.

Distribution of COVID-19 disease, length of hospital stay, intensive care unit (ICU) requirement and mortality were compared according to $\mathrm{ABO}$ blood groups. In addition, comparison of $\mathrm{ABO}$ blood group distribution with normal healthy population was made.

\section{Statistical Analysis}

SPSS 21.0 (IBM, NY, USA) program was used for statistical analysis. The normality of the distribution was evaluated by the Kolmogorov-Smirnov test. Mean and standard deviation values and percentages are specified. Chi square and ANOVA were used to compare the groups. Significant $\mathrm{p}$ value was chosen as $<0.05$.

\section{RESULTS}

A total of 179 patients with confirmed COVID-19 and 5200 healthy control patients were included in the study. About $51 \%$ of patients diagnosed with 
Table 1. Comparison of the mean age of male and female patients with COVID-19

\begin{tabular}{|lllllll|}
\hline & & Mean \pm Std & Min-Max & Median & f & p \\
\hline \multirow{2}{*}{ Age (years) } & Female $(\mathrm{n}=91)$ & $53.19 \pm 18.92$ & $0-92$ & 56 & 2.694 & 0.637 \\
& Male $(\mathrm{n}=88)$ & $53.44 \pm 21.27$ & $0-95$ & 59 & & \\
& Total $(\mathrm{n}=179)$ & $53.31 \pm 20.05$ & $0-95$ & 58 & & \\
\hline
\end{tabular}

\begin{tabular}{|c|c|c|c|}
\hline & & $n=179)$ & $\%$ \\
\hline \multirow[t]{3}{*}{ A group } & A Rh - & 9 & 5.03 \\
\hline & $A R h+$ & 102 & 56.98 \\
\hline & Total & 111 & 62.01 \\
\hline \multirow[t]{3}{*}{ B group } & $B R h$ - & 3 & 1.68 \\
\hline & B Rh + & 14 & 7.82 \\
\hline & Total & 17 & 9.50 \\
\hline \multirow[t]{3}{*}{ AB group } & AB Rh - & 3 & 1.68 \\
\hline & $\mathrm{AB} R \mathrm{Rh}+$ & 13 & 7.26 \\
\hline & Total & 16 & 8.94 \\
\hline \multirow[t]{3}{*}{ O group } & O Rh - & 5 & 2.79 \\
\hline & $\mathrm{ORh}+$ & 30 & 16.76 \\
\hline & Total & 35 & 19.55 \\
\hline
\end{tabular}

COVID-19 were women (91/179). The mean age of the patients was $53.31 \pm 20.05$. In addition, the average age of female patients was $53.19 \pm 18.92$ years, while male patients were $53.44 \pm 21.27$ years. No significant difference was found between gender and the mean age of the patients $(\mathrm{p}=0.637)$ (Table 1$)$.

According to the blood groups of patients with COVID-19, the rate of RH (-) in patients with COVID-19 was very low in all blood groups. In addition, patients with COVID-19 showed a distribution of $62.01 \%$ in group A, $9.50 \%$ in group B, $8.94 \%$ in group $\mathrm{AB}$ and $19.55 \%$ in group $\mathrm{O}$ (Table 2 ).

While the proportion of women in group A with the highest population of patients was $33.51 \%$, the rate of men was $28.49 \%$. In general, there was a significant difference between blood groups and gender $(p=0.009)$. Besides, there was a statistically signifi- cant difference between blood group A and gender ( $p<0.001$ ), but there was no significant difference between other groups ( $p>0.05$ ) (Table 2).

When ICU hospitalization status of COVID-19 patients was analyzed according to blood groups, 22 $(12.29 \%)$ patients in group A, $2(1.12 \%)$ patients in group B, $4(2.23 \%)$ patients in group $\mathrm{O}$ and 13 in group $\mathrm{O}(7.26 \%)$ were found to be hospitalized in the ICU. This situation was not statistically significant ( $p>0.05)$. In group A, length of stay in ICU was longer (10.42 \pm 11.61 days). There was a statistically significant difference between the duration of stay in ICU and the group A patients ( $\mathrm{p}=0.013)$ (Table 3).

Patients with exitus due to COVID-19 were observed mostly in group A with a rate of $7.26 \%$, this was observed in group $\mathrm{O}$ with a rate of $3.35 \%$. This situation was found to be statistically significant $(\mathrm{p}=$ 0.032) (Table 3).

Compared to the blood groups of the healthy control group, COVID-19 patients had higher A blood group than the healthy group (62 \& vs. $46.6 \%$; $\mathrm{p}<$ $0.001)$ and lesser of the $O$ blood group (19.6\% vs. $34.7 \%$; $<<0.001$ ) detected (Table 4).

\section{DISCUSSION}

As a result of this study, A blood group is the most common in patients diagnosed with COVID-19. Compared to the control group, it was found that the blood group A was more common in the COVID-19 patients than the control group and that the $\mathrm{O}$ blood group was less common than the control group. It was found that patients with blood group A had a longer stay in ICU and these patients had a higher mortality rate.

ABO blood groups have been determined to have predictive effects in various diseases. ${ }^{11-13}$ Animal 
International Journal of Hematology and Oncology

\begin{tabular}{|c|c|c|c|c|c|c|c|}
\hline & & Group A & Group B & Group AB & Group 0 & t test & $\mathbf{p}$ \\
\hline Length of Hospital & Mean \pm Std & $9.32 \pm 6.31$ & $9.17 \pm 3.79$ & $9.51 \pm 5.83$ & $10.34 \pm 9.66$ & 1.211 & 0.722 \\
\hline \multirow[t]{2}{*}{ Stay (day) } & $\mathrm{p}$ & 0.478 & 0.712 & 0.853 & 0.531 & & \\
\hline & $95 \% \mathrm{Cl}$ & $(8.13-10.51)$ & $(7.22-11.12)$ & $(6.39-12.61)$ & $(7.02-13.66)$ & & \\
\hline \multirow[t]{2}{*}{ ICU Requirement } & Yes & 22 (12.29\%) & $2(1.12 \%)$ & $4(2.23 \%)$ & $13(7.26 \%)$ & 5.818 & 0.121 \\
\hline & No & 89 (49.72\%) & 15 (8.38\%) & $12(6.70 \%)$ & 22 (12.29\%) & & \\
\hline Length of ICU & Mean \pm Std & $10.42 \pm 11.61$ & $4.50 \pm 0.70$ & $8.51 \pm 6.81$ & $9.47 \pm 13.91$ & 4.486 & 0.143 \\
\hline \multirow[t]{2}{*}{ Stay } & $\mathrm{p}$ & 0.013 & 0.578 & 0.663 & 0.412 & & \\
\hline & $95 \% \mathrm{Cl}$ & $(9.21-11.63)$ & $(3.31-5.71)$ & (7.32-9.70) & $(7.91-11.03)$ & & \\
\hline \multirow[t]{3}{*}{ Exitus } & Yes & $13(7.26 \%)$ & $1(0.56 \%)$ & $2(1.12 \%)$ & $6(3.35 \%)$ & 2.374 & 0.032 \\
\hline & No & 98 (54.75\%) & 16 (8.94\%) & $14(7.82 \%)$ & 29 (16.20\%) & & \\
\hline & $p$ & 0.027 & 0.924 & 0.634 & 0.042 & & \\
\hline
\end{tabular}

studies have shown that the adhesion of the SARS virus to the S protein / angiotensin converting enzyme 2 is specifically inhibited by monoclonal or human natural anti-A antibodies, and these antibodies disrupt the interaction between the virus and its receptor, creating a protective mechanism. ${ }^{14}$ In this study, it was observed that A blood group was more in line with the literature.

Recently, studies evaluating the effect of $\mathrm{ABO}$ blood groups in COVID-19 disease caused by SARS-CoV-2 have been published. In a study of 265 COVID-19 patients, Li et al. reported that COVID-19 disease was seen more in patients with group $\mathrm{A}$ and less in patients with group $\mathrm{O}$ blood than in normal population. ${ }^{5}$ In following studies, it was found that the patients with A blood group were more than the control group and that the $\mathrm{O}$ blood group was seen less than the control patients. ${ }^{4,15,16}$ In these studies, the protective effect of Anti A antibody is emphasized. In another recent study con- ducted in Turkey, there was no significant difference between ABO blood groups. ${ }^{17}$ However, Rh - blood group is supported to be protective. In our study, the $\mathrm{Rh}+$ ratio of COVID-19 patients was statistically significantly higher. In addition to clinical studies, a new susceptibility locus was detected in a chromosome 3p21.31 gene cluster and the potential effect of the ABO blood group system on COVID-19 was confirmed. ${ }^{18}$ In this study, the association signal at the $9 \mathrm{q} 34.2$ locus coincided with the ABO blood group locus. A higher risk was shown in blood group A compared to other blood groups (OR: 1.45; 95\% CI: $\left.1.20-1.75 ; \mathrm{p}=1.48 \times 10^{-4}\right)$. Also, it was found to have a protective effect in O blood group compared to other blood groups (OR: $0.65 ; 95 \% \mathrm{CI}$ : $\left.0.53-0.79 ; \mathrm{p}=1.06 \times 10^{-5}\right)$.

In our study, it was concluded that COVID-19 disease was associated with $\mathrm{ABO}$ blood groups. However, it was found that blood type A had negative effects on COVID-19-related mortality. Although the

\begin{tabular}{|c|c|c|c|c|}
\hline & A & B & AB & 0 \\
\hline Control Group $(n=5221)$ & 2430 (46.6\%) & $639(12.2 \%)$ & 341 (6.5\%) & $1810(34.7 \%)$ \\
\hline Patients $(n=179)$ & $111(62 \%)$ & $17(9.5 \%)$ & 16 (8.9\%) & 35 (19.6\%) \\
\hline$\chi^{2}$ & 16.602 & 1.221 & 1.622 & 17.591 \\
\hline$p$ value & $<0.001$ & 0.269 & 0.203 & $<0.001$ \\
\hline
\end{tabular}


A blood group did not increase the need for ICU, it was observed that the ICU hospitalization period was longer and the mortality was higher.

The limitations of the study are; sample size is small. Another limitation is that $\mathrm{Rh}(-)$ patients cannot be evaluated statistically due to the low number of patients.

Blood group A can be used as a predictive biomarker for COVID-19 disease. Specifically, we concluded that the group A had a higher risk for COVID-19 disease and severity. Prospective larger multicenter studies are needed to explain the possible predictive role of $\mathrm{ABO}$ blood groups.

\section{REFERENCES}

1. Chen L, Liu W, Zhang $Q$, et al. RNA based mNGS approach identifies a novel human coronavirus from two individual pneumonia cases in 2019 Wuhan outbreak. Emerg Microbes Infect 9: 313-319, 2020.

2. Coronavirus disease (COVID-19) pandemic. https:// www.who.int/docs/default-source/coronaviruse/ situation-reports/20200311-sitrep-51-covid-19. pdf?sfvrsn=1ba62e57_10 (Access Date 01/06/2020).

3. Coronavirus disease (COVID-19) Situation Report - 134 2020. https://www.who.int/docs/default-source/coronaviruse/situation-reports/20200602-covid-19-sitrep-134. pdf?sfvrsn=cc95e5d5_2 (Access Date 02/06/2020).

4. Zhao J, Yang $\mathrm{Y}$, Huang $\mathrm{H}$, et al. Relationship between the ABO Blood Group and the COVID-19 Susceptibility. medRxiv. 2020: 2020.03.11.20031096.

5. Li J, Wang X, Chen J, et al. Association between ABO blood groups and risk of SARS-CoV-2 pneumonia. Br J Haematol 190: 24-27, 2020.

6. Chen N, Zhou M, Dong X, et al. Epidemiological and clinical characteristics of 99 cases of 2019 novel coronavirus pneumonia in Wuhan, China: a descriptive study. Lancet 395: 507-513, 2020.

7. Reid ME, Bird GW. Associations between human red cell blood group antigens and disease. Transfus Med Rev. 1990;4: 47-55, 1996.

8. Pinkston JA, Cole P. ABO blood groups and salivary gland tumors (Alabama, United States). Cancer Causes Control 7: 572-574, 1996

9. Tyagi SP, Tiagi GK, Pradhan S. ABO blood groups in relation to cancer cervix. Indian J Med Sci 21: 611-615, 1967.

10. Batool Z, Durrani SH, Tariq S. Association of ABO and Rh blood group types to hepatitis $B$, hepatitis $C$, HIV and syphilis infection, a five year' experience in healthy blood donors in a tertiary care hospital. J Ayub Med Coll Abbottabad 29: 90-92, 2017.
11. Lindesmith L, Moe C, Marionneau S, et al. Human susceptibility and resistance to Norwalk virus infection. Nat Med 9: 548-553, 2003.

12. Cheng $\mathrm{Y}$, Cheng $\mathrm{G}$, Chui $\mathrm{CH}$, et al. $\mathrm{ABO}$ blood group and susceptibility to severe acute respiratory syndrome. JAMA 293: 1450-1451, 2005.

13. Borén T, Falk P, Roth KA, Larson G, Normark S. Attachment of Helicobacter pylori to human gastric epithelium mediated by blood group antigens. Science 262: 1892-1895, 1993.

14. Guillon $P$, Clément $M$, Sébille $V$, et al. Inhibition of the interaction between the SARS-CoV spike protein and its cellular receptor by anti-histo-blood group antibodies. Glycobiology 18: 1085-1093, 2008.

15. Zietz M, Tatonetti NP. Testing the association between blood type and COVID-19 infection, intubation, and death. medRxiv. 2020: 2020.04.08.20058073.

16. Goker H, Aladag Karakulak E, Demiroglu H, et al. The effects of blood group types on the risk of COVID-19 infection and its clinical outcome. Turk J Med Sci 50: 679-683, 2020.

17. Arac E, Solmaz I, Akkoc H, et al. Association between the Rh blood group and the Covid-19 susceptibility. UHOD-Int J Hematol Oncol 30: 81-86, 2020.

18. Ellinghaus D, Degenhardt F, Bujanda L, et al. Genomewide Association study of severe Covid-19 with respiratory failure. NEJM 2020, Jun 17. doi: 10.1056/NEJMoa2020283. Online ahead of print.

\section{Correspondence:}

\section{Dr. Sude Hatun AKTIMUR}

Samsun Egitim ve Arastirme Hastanesi

Kisla, Baris Blv. No: 199,

55090 Ilkadim

SAMSUN / TURKEY

e-mail: sudehatun@yahoo.com

tel: (+90-532) 6685646

\section{ORCIDs:}

Sude Hatun Aktimur

0000-0002-7468-1721

Ahmet Sen

0000-0002-7026-2976

Bahadir Yazicioglu

$0000-0003-4397-2769$

Ahmet Kursad Gunes

0000-0001-5522-8342

Serhat Genc
0000-0001-8621-9692 